\title{
C) Histontórica
}

História e historiografia da imprensa angolana oitocentista: notas teóricas e metodológicas

\author{
History and historiography of press angolan nineteenth century: theoretical and \\ methodological notes
}

\section{Eduardo Antonio Estevam Santos*}

Resumo: Este artigo interpreta historicamente a produção de periódicos na segunda metade do século XIX, apresentando um balanço do estado da arte, as metodologias empregadas, as dinâmicas e particularidades desse tipo de imprensa, assim como, analisa as circunstâncias do seu lugar de inserção, suas ligações com diferentes poderes, recepção e audiência no âmbito do sistema colonial português.

Palavras-chave: Imprensa, Política Colonial, Historiografia.

Abstract: This article interprets, on a historical basis, the making of periodicals in the second half of the nineteenth-century. It presents an overview of the specialised literature, methodologies employed, dynamics and nuances of this kind of press, as well as analyses its contextual insertion, its links with various powers, receptions and audiences within the Portuguese colonial system.

Keywords: Press, Colonial Policies, Historiography.

Este artigo pretende contribuir para a historiografia da imprensa angolana, mais precisamente, para a escrita da História de Angola por meio da imprensa. Nosso marco temporal tem início em I845, com o surgimento do Boletim do Governo Geral da Província de Angola (doravante mencionaremos sob a sigla BOA, Boletim Oficial de

\footnotetext{
" Professor adjunto do Instituto de Humanidades e Letras do campus dos Malês da Universidade da Integração Internacional da Lusofonia Afro-Brasileira (Unilab). Membro do Grupo de Estudos sobre Territórios Atlânticos (GETA) da Universidade Federal de Alagoas (UFAL), vinculado ao Conselho Nacional de Desenvolvimento Científico e Tecnológico (CNPq). E-mail: eduardoestevame@unilab.edu.br. Este trabalho foi apresentado no Simpósio Temático Histórias de África, Histórias da Diáspora: diálogos, abordagens, conexões, parte integrante do I2 $^{\circ}$ Encontro Nacional de História e I $^{\mathbf{o}}$ Encontro Internacional de História da Universidade Federal de Alagoas, realizado virtualmente entre os dias 8 e io de setembro de $202 \mathrm{I}$.
} 
Angola), e a década de I890, o encerramento desse ciclo, quando finalmente às pretensões de Portugal em África foram asseguradas internacionalmente, repercutindo na feição editorial da imprensa. Nessa nova fase (LAINS,I998, p. 476), passou-se rapidamente do momento liberal, quanto ao comércio e à administração, para um novo sistema colonial. Sendo assim, esta pesquisa situa-se no âmbito das políticas liberais promovidas pela revolução liberal do Porto que, ao promulgar a primeira constituição liberal (I822), estabeleceu como princípio a integração e a igualdade jurídica do território nacional, incluindo a representação dos territórios ultramarinos nas Cortes, mas, do outro lado do atlântico, se deparava com fortes tensões, pressões e lutas, que procuravam por meio da imprensa livre resolver os problemas conceituais da diversidade, para que não se tornassem uma mera ilusão de uniformidade. Depois da independência do Brasil, Angola passou a ser a colônia mais potente do império colonial português, dessa forma, e de acordo com as conjunturas estudadas, a imprensa angolana apresenta uma série de especificidades históricas.

As constantes reflexões e inovações das práticas historiográficas no século XX desconstruíram a tese de que a imprensa era uma fonte pouco adequada para investigar o passado, uma vez que, era um tipo de material produzido "sob o influxo de interesses, compromissos e paixões" (DE LUCA, 2005, p. II2), no entanto, escovando a história a contrapelo (BENJAMIN, 1985, 222-234), esses materiais, indubitavelmente são imprescindíveis fontes de pesquisas para os estudos da histórica social e cultural. Desde então, quando possível, a imprensa tornou-se o lócus por excelência para a pesquisa histórica. Inúmeros trabalhos sobre os mais variados temas da história de Angola fizeram uso dos materiais impressos e da imprensa periódica, desde o seu advento, ora como a principal fonte histórica ou como subsidiária. Sabemos que na ausência de fontes ${ }^{\mathrm{I}}$ escritas (no sentido stricto) às tradições orais tem compensado bastante as investigações que procurem realizar interpretações históricas, salientamos, como observa Joseph Miller (I999, p. IO), que tal lacuna, não caracteriza a falta de criação, preservação e reprodução de conhecimentos pelos agentes históricos envolvidos.

A imprensa propaga os inventos da sciencia, - explica-os, discute-os, e aperfeiçoa-os: a imprensa registra os fatos, comenta-os, analisa-os,

\footnotetext{
${ }^{\text {I }}$ Fonte Histórica é tudo aquilo que, por ter sido produzido pelos seres humanos ou por trazer vestígios de suas ações e interferência, pode nos proporcionar um acesso significativo à compreensão do passado humano e de seus desdobramentos no Presente (BARROS, 20I9, s/p).
} 


\section{C) GitistóróRICA}

e deduz deles consequências cuja utilidade nos mostra a história; a imprensa examina as instituições, critica-as e corrigeas: - coíbe os poderes e adoça lhes a natural agrura do mando, - é o fiscal do governo, e, como órgão da opinião pública, representa perante eles de procurador, advogado, e tribuno do povo. ${ }^{2}$

O número crescente de periódicos pode ser atribuído à lei liberal que ampliou as garantias constitucionais da liberdade de imprensa, a lei de 22 de maio de i866. A citação acima fazia parte desse decreto. Em todo o século XIX foram publicados 59 periódicos, um pouco mais de 70\% desses impressos tiveram uma curta duração. Contudo, para uma interpretação histórica desses materiais, apresentaremos um balanço do estado da arte, as metodologias empregadas, as dinâmicas e particularidades deste tipo de imprensa, assim como, uma análise das circunstâncias do seu lugar de inserção, suas ligações com diferentes poderes, recepção e audiência no âmbito do sistema colonial português.

Segundo o decreto publicado no $B O A$ no dia I2 de fevereiro de I857 sobre as restrições à liberdade de imprensa, entendia-se por imprensa periódica, toda a estampa, escrito impresso ou litografado, publicados em dias certos ou irregulares, que contivesse notícias ou matérias religiosas, políticas ou atos da vida particular de qualquer pessoa, que pudesse resultar em infâmia, desonra ou injúria, e que não excedesse seis folhas de impressão. ${ }^{3}$

A história da imprensa angolana tem início ${ }^{4}$ em 1836, quando o ministro Bernardo de Sá Nogueira e Figueiredo (I785-1876), mais conhecido como Sá da Bandeira (ministro da Marinha entre os anos de I835-37, I856-59, I865 e I870) autorizou no artigo $13 .^{\circ}$ do decreto de 7 de dezembro a criação nas possessões ultramarinas portuguesas publicações que pudessem transmitir informações militares, civis, legais, comerciais e gerais. O BOA foi pioneiro, sua primeira edição foi em I845, mas, existe um

\footnotetext{
${ }^{2}$ Decreto de 22 de maio de I866, do Ministério dos Negócios Eclesiásticos e de Justiça, Direção Geral dos Negócios da Justiça.

3 Boletim do Governo Geral da Província de Angola, I2 de fevereiro de I857, p.4.

4 Alguns autores, como Licurgo Costa, Barros Vidal e Lawrence Hallewell, afirmam que, nos séculos I6 e I8, já teria existido algum prelo em Angola. No caso de Barros Vidal, seriam dois prelos, instalados, respectivamente, em Luanda e em São Salvador do Congo (Mbanza Kongo). No caso de Hallewell, a referência seria aos primeiros jesuítas que, a exemplo do que fora praticado em Goa, teriam levado consigo um prelo. Contudo, diz ele, nenhum pesquisador ou historiador até hoje, em especial Júlio de Castro Lopo, que é seu grande estudioso, jamais comprovou a veracidade de tais informações ou encontrou provas documentais que sustentassem tais hipóteses (HOHLFELDT, 20I2, p. 90).
} 
episódio ainda não plenamente investigado pelos historiadores, que antecipa o surgimento da imprensa para o ano de i842. O ex-escrivão da fazenda e deputado por Angola, Joaquim António de Carvalho e Menezes, havia solicitado autorização ao governador para aquisição da maquinaria necessária para fundar o primeiro periódico. Segundo o periodista José de Fontes Pereira, por meio do seu artigo A Independência de Angola, escrito em I886, o ministro dos negócios da marinha e ultramar, empregou todos os meios necessários para afundar o navio (os passageiros salvaram-se) que estaria trazendo o material tipográfico (PINTO, 20I7, pp. 508-509).

A imprensa não oficial teve sua primeira aparição em I852 com o periódico Almanak Estatístico da Província de Angola e suas Dependências, que segundo Júlio de Castro Lopo, preocupava-se com as notícias do governo e informações genéricas sobre clima, população, religião, comércio e indústria, cujo objetivo era satisfazer o leitor com curiosidades e aprofundamento de assuntos da história de Angola. Fundado por dois militares, um advogado e um funcionário do governo, o Aurora, foi o terceiro semanário fundado em Angola, em I856, impresso pela tipografia do governo, suas intenções eram exclusivamente literárias.

O primeiro periódico noticioso, que inaugurou a chamada imprensa livre, $A$ Civilisação da África Portuguesa, teve o seu primeiro número editado em o6 de dezembro de I866, esse impresso foi um marco na história do jornalismo angolano. Alguns meses depois, surgiu o Comércio de Luanda. Na década de 1870 surgiram mais 7 periódicos, $O$ Progresso (I870), O Mercantil (I870), O Almanach Popular (1872), O Cruzeiro do Sul (I873), O Meteoro (1873), Correspondência de Angola (1875) e o Jornal de Luanda (1878). O Progresso surgiu em Benguela. O Almanach era composto e impresso nas oficinas do Mercantil. $O$ Correspondência de Angola foi um jornal noticioso, literário e político e, assim como $O$ Meteoro, também teve uma curta duração. Não era comum apresentar a tiragem das edições, apenas $O$ Mercantil o mencionava, com publicações semanais, sua tiragem era de 700 exemplares. Esse periódico foi o semanário de maior duração (vide tabela) na segunda metade do século XIX em toda Angola. Enquanto na Europa e nos Estados Unidos às tipografias modernas eram movidas a vapor e imprimiam I.IOo exemplares por hora, em Angola, com publicações semanais, essas máquinas (prensa mecânica) eram mais modestas, imprimiam entre 500 a 700 exemplares, para os casos das tipografias mais avançadas. 


\section{C) GitistóróRICA}

Novos temas dominaram a pauta política e influenciaram no surgimento de novos periódicos, tais como, os debates internacionais acerca da nova política colonial (Conferência de Berlim I884-I885), as influências do republicanismo português e brasileiro e o movimento contestatório dos filhos do país. A elite letrada, principalmente mestiça, acreditava que nos ideais republicanos poder-se-ia concretizar a igualdade jurídica conforme preconizava a constituição portuguesa e combater de forma mais eficaz as práticas escravagistas (embora abolida em I878). Houve uma explosão de novas publicações, dos 59 periódicos de todo o século XIX, 4I surgiram nas décadas de I880 e I890.

Quadro I: Periódicos disponíveis para pesquisa na Biblioteca Nacional de Portugal ${ }^{5}$

\begin{tabular}{|c|c|c|}
\hline Títulos/Duração & Localização & Notas \\
\hline \multirow[t]{2}{*}{$\begin{array}{l}\text { Boletim do Governo Geral da } \\
\text { Província de Angola (I845) }\end{array}$} & Biblioteca Nacional de Portugal & $\begin{array}{l}\text { Anos de I866, } \\
\text { I867,I890, I89I em } \\
\text { mau estado }\end{array}$ \\
\hline & Universidade de Coimbra/Biblioteca Geral & $\begin{array}{l}\text { I845-I9II (Faltas: } \\
\text { I868-I873; I876- } \\
\text { I88I) }\end{array}$ \\
\hline $\begin{array}{l}\text { Almanak Estatístico da } \\
\text { Província d'Angola e suas } \\
\text { Dependências (1852) }\end{array}$ & Não há registros & \\
\hline Aurora (I856) & Não há registros & \\
\hline $\begin{array}{l}\text { A Civilisação da África } \\
\text { Portuguesa (I866-I869) }\end{array}$ & $\begin{array}{l}\text { Biblioteca Nacional de Portugal/Fundo Geral } \\
\text { Monografias }\end{array}$ & $\begin{array}{l}\text { N. I (6 Dez. I866)- } \\
\text { n. I52 (26 Set. } \\
\text { I869) }\end{array}$ \\
\hline $\begin{array}{l}\text { O Comércio de Luanda (I867- } \\
\text { I870) }\end{array}$ & Biblioteca Nacional de Portugal & $\begin{array}{l}\text { N. I (I8 Set. I867) } \\
\text { N. II7 (8 Jan. I870) }\end{array}$ \\
\hline $\begin{array}{l}\text { O Mercantil (I870-I89I, I896- } \\
\text { I897) }\end{array}$ & Biblioteca Nacional de Portugal & 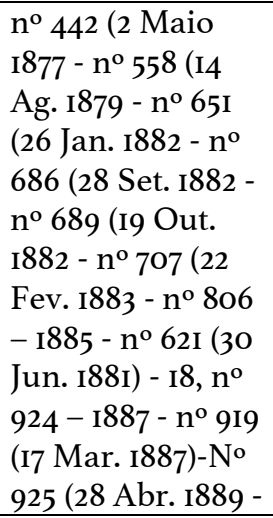 \\
\hline O Almanaque Popular (I872) & Não há registros & \\
\hline O Meteoro (I873) & Não há registros & \\
\hline O Cruzeiro do Sul (I873-I878) & Biblioteca Nacional de Portugal & $\begin{array}{l}\text { N. I (I6 jun. I873) - } \\
\text { no } 284 \text { ( } 27 \text { jun. } \\
\text { I878) }\end{array}$ \\
\hline $\begin{array}{l}\text { Correspondência de Angola } \\
\text { (I875) }\end{array}$ & Biblioteca Nacional de Portugal & N. I (29 jul. I875) \\
\hline
\end{tabular}

5 É importante salientar que todos esses dados estão disponíveis no site https://porbase.bnportugal.gov.pt, consulta realizada em I9/09/202I.No campo Notas as letras N indicam o número das edições disponíveis. 
Jornal de Luanda (I878-I882)

Noticiário de Angola (I880)

Boletim da Sociedade

Propagadora de

Conhecimentos Geográfico-

Africano de Luanda (I88I)

Gazeta de Angola (I88I)

O Echo de Angola (I88I-I882)

\begin{tabular}{|l|} 
\\
\hline O Jornal de Mossamedes -
\end{tabular}

(I88I-I882)

O Ultramar (I882)

A Verdade (I882)

A União Áfrico-portuguesa (I882-I883)

O Raio (I884)

O Bisnaga (I884)

O Futuro de Angola (I882-

I894)

O Pharol do Povo (I883-I885)

O Rei Guilherme (I886)

O Arauto dos Concelhos (I886)

O Serão (I886)

A Tesourinha (I886)

O Exército Ultramarino (I887I888)

O Progresso de Angola (I887)

O Foguete (I888)

Mukuarimi (I888)

Muen Exi (I889)

Arauto Africano (I889-I890)

O Desastre (I889-I890)

O Tomate (I889-I89I)

O Correio de Luanda (I890)

O Chicote (1890)

Os Concelhos de Leste (I89I)

Notícias de Angola (I89I)

O Polícia Africano (I890-I89I)

Commércio d'Angola (I892)

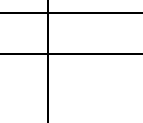

Bibi

Biblioteca Nacional de Portugal

Biblioteca Nacional de Portugal

Biblioteca Nacional de Portugal

Não há registros

Não há registros

\begin{tabular}{|l|l} 
& I882) \\
\hline Não há registros &
\end{tabular}

N. I7 (I7 nov. I88I)

N. I (I2 nov. I88I)

- N. 9 (I8 fev.

882)

Não há registros

Biblioteca Nacional de Portugal

N. I (I2 fev. I882) -

N. 57 (23 out. I888)

N. I (6 maio I882)

Biblioteca Central da Marinha

Biblioteca Nacional de Portugal

- N. 60 (2I mar I883) Não há registros Não há registros

Biblioteca Nacional de Portugal

A. I, n. I (4 Mar. I882)-a. I2, N. 206 (I4 Jun. I894) N. I (Io fev. I883) a. 3, N. I32 (II nov. I885)

Biblioteca Nacional de Portugal N. I (9 out. I886)

Biblioteca Nacional de Portugal

N. I (9 out. 1886)

N. I (IO set. I886) N. 2 (IO out. I886)

Biblioteca Nacional de Portugal

N. 2 (IO out. 1886)

Não há registros

Biblioteca Nacional de Portugal

N. I (IO nov. I887)

- N. 7 (Io maio I888)

O Sul de Angola (I892-I893) Não há registros Não há registros Não há registros

N. I, (2 Jun. I889)

N.. 2 (23 Jun. I889)

N. I (I7 Mar. I889)

N. 9 (I9 Maio I889)

N. I, (30 set. I889)

-N. I7 (7 maio

I893)

Biblioteca Nacional de Portugal

A. I (8 Fev. I89I)

\begin{tabular}{|c|}
\hline Biblioteca Nacional de Portugal \\
\hline Não há registros \\
\hline Não há registros \\
\hline Não há registros \\
\hline Não há registros \\
\hline
\end{tabular}

Biblioteca Nacional de Portugal

N. I, (I2 jul. I892)

N. 52 (2I dez. I893)

Biblioteca Nacional de Portugal 


\begin{tabular}{|l|l|l|}
\hline \multicolumn{2}{|l|}{ Crútica } & $\begin{array}{l}\text { N. 2, 23 (4 out. } \\
\text { I893) }\end{array}$ \\
\hline A Província (I893) & Biblioteca Nacional de Portugal & $\begin{array}{l}\text { N. 30 (I8 mar. } \\
\text { I894) }\end{array}$ \\
\hline O Independente (I894) & Biblioteca Nacional de Portugal & N. I, (I maio I894) \\
\hline Bofetadas (I894-I895) & Biblioteca Nacional de Portugal & $\begin{array}{l}\text { N. I, (25 out. I894) } \\
\text { N. 25 (30 abr. } \\
\text { I895) }\end{array}$ \\
\hline O Imparcial (I894-I895/I898 & Biblioteca Nacional de Portugal & $\begin{array}{l}\text { N. I, (26 abr. I894) } \\
\text { N. I9 (I9 ag. I894) }\end{array}$ \\
\hline Propaganda Colonial (I896) & Biblioteca Nacional de Portugal & $\begin{array}{l}\text { Descrição } \\
\text { baseada em: v. I, } \\
\text { fasc. 4 (I896) }\end{array}$ \\
\hline O Santelmo (I896) & Não há registros & \\
\hline Revista de Luanda (I896) & Biblioteca Nacional de Portugal & $\begin{array}{l}\text { N. I, (I abr. I896) } \\
\text { N. 4 (I out. I896) }\end{array}$ \\
\hline Propaganda Angolense (I897) & Não há registros & \\
\hline A Folha de Luanda (I899) & Não há registros & \\
\hline
\end{tabular}

Fonte: Biblioteca Nacional de Portugal.

As fontes de pesquisa provenientes de acervos e/ou repositórios digitais tem contribuído de forma bastante eficaz para as pesquisas históricas. O campo da história digital tornou-se uma área promissora, uma das formas possíveis de mediação para abordar e analisar o passado utilizando as novas tecnologias de comunicação. Até o momento da construção deste artigo constatamos que a Biblioteca Nacional do Brasil, em sua seção Hemeroteca Digital, disponibilizava gratuitamente a coleção completa do periódico A Civilisação da África Portuguesa. No entanto, a Biblioteca Nacional de Portugal disponibiliza um número mais amplo de títulos (conforme demonstra o quadro I), com custos para reprodução e envio eletronicamente. Nem todos os títulos estão disponíveis em sua integridade, em função do estado de conservação. Não encontramos registros na rede mundial de computadores (internet) sobre a existência de serviços digitais do acervo da Biblioteca Nacional de Angola, fomos informados, por meio de uma comunicação eletrônica (e-mail), que esses materiais de pesquisa se encontram em suporte físico e que as pesquisas só poderiam ser realizadas de forma presencial. Em 2019, em entrevista concedida ao Jornal de Angola, o diretor-geral da Biblioteca, João Pedro Lourenço, afirmou que essa instituição estava em processo de modernização. ${ }^{6}$

Percorrer o caminho que vai da desconsideração à centralidade dos periódicos, como bem observa a pesquisadora Tânia Regina de Luca, na produção do saber

\footnotetext{
6 Jornal de Angola, I5 de outubro de 20I9, consulta realizada em I3 de maio de 202I,
} www.jornaldeangola.ao. 
histórico, implica acompanhar, ainda que de forma bastante sucinta, a renovação dos temas, às problemáticas e os procedimentos metodológicos da disciplina (DE LUCA, 2005, p. II2). Por vezes, os pesquisadores que fizeram uso do periodismo, apenas como fonte secundária, acessória ou mediadora dos seus estudos, demonstraram pouca preocupação com as questões fundamentais para esse tipo de documentação: como, onde, para quem foram produzidos esses periódicos? Ainda que esses pesquisadores reconhecessem na imprensa um instrumento político de influência, manipulação e intervenção na vida social e que a mesma ajudou a dar forma aos eventos que registrava. Importantes trabalhos seminais tiveram por base o BOA. José de Almeida Santos (I922-1997) publicou dezenas de livros, merece destaque, para o nosso estudo, àqueles que se debruçaram sobre a história social de Luanda no século XIX, que fizeram uso da imprensa. Vinte anos decisivos na vida de uma cidade I845-I864, publicado em I870, um livro com mais de 500 páginas, reproduz em seu anexo, como documentos, uma série artigos constantes no BOA. O renomado intelectual Mário António Fernandes de Oliveira publicou o artigo Aspectos sociais de Luanda inseridos nos anúncios publicados na sua imprensa, cuja intenção era analisar aspectos da vida social de Luanda, tais como comércio, escravidão, imóveis, serviços, relações pessoais e espólio. Mas, sem dúvida, os trabalhos do Júlio de Castro Lopo são nomeadamente um marco na historiografia da imprensa angolana. Esse pesquisador nasceu em Valpaços (Portugal), em I899, morou em Angola por mais de cinquenta anos e morreu em I97I no mesmo local do seu nascimento. Foi funcionário público, mas, a sua grande paixão foi a investigação. Para a História da Imprensa de Angola, publicado em 1962 e Jornalismo de Angola - subsídios para a sua história, editado em 1964, são as suas principais contribuições para a historiografia da imprensa angolana. Em linhas gerais, Lopo estava preocupado com a evolução da imprensa periódica e jornalística angolana, por meio de análises que se pautaram mais nas descrições evolutiva dos materiais impressos que na articulação entre os processos históricos que os influenciaram ideologicamente.

Rosa Cruz e Silva deu uma importante contribuição para os estudos da imprensa angolana, ao trazer para o público em geral uma breve descrição de 26 títulos de periódicos, no ano de 1997, como uma amostragem, num período em que os meios de pesquisas acadêmicas digitais não eram tão populares. Em Os periódicos como fonte de pesquisa histórica - a imprensa escrita de Angola do séc. XIX, Rosa Cruz, tinha por base os estudos do Castro Lopo. Esse trabalho consistia num material de divulgação do 


\section{C) Hitistór RICA}

acervo do Arquivo Histórico Nacional de Angola, como uma atividade alusiva às comemorações da independência desse país e, no momento da publicação, a referida historiadora era Diretora desta instituição. Os dados do levantamento apresentado informavam que existia no Arquivo Histórico títulos de periódicos publicados em Ambriz, Benguela, Catumbela, Mossamedes e Luanda, perfazendo um total de 59, dos quais 33, constavam na lista dos periódicos da Biblioteca Municipal de Luanda.

Os constantes anúncios de escravos recapturados publicados no $B O A$ revelaram na pesquisa do historiador José Curto uma verdadeira cultura de resistência à escravidão. Em Resistência à escravidão em África: o caso dos escravos fugitivos recapturados em Angola, entre os anos de I846 e I876, Curto descreve nesse ensaio que registou mais de três mil casos de escravos fugitivos recapturados. Concluiu que o processo contínuo de fugas até o ano de 1876 demonstrava que os escravizados não acreditavam nas legislações abolicionistas. Mais um exemplo, dentre inúmeros, da escrita da história de Angola por meio da imprensa. Apesar de não ser uma historiadora dos estudos impressos, Jill Dias (1998, p. 529) também fez uso desses materiais para a sua escrita da história, reconhecendo que a partir de 1860 o periodismo tornou-se o principal veículo dos descontentamentos de todos os níveis econômicos e sociais da colônia e da luta para influenciar e pressionar o governo de Lisboa. Para René Pélissier (2016, p. 136) a imprensa oitocentista foi um fórum de exposições de ideias e críticas, um veículo para a realização de reformas. Esse historiador observa ainda que, os periodistas mestiços escreviam seus editoriais em quimbundo para convencer as autoridades e os colonos portugueses do ponto de vista angolano e, como havia poucos oficiais portugueses que compreendiam o quimbundo, publicar nessa língua seria algo absurdo. No entanto, desde o momento em que Portugal impôs o português como língua oficial em I845, como forma de resistência, os filhos do país (SANTOS, 2020, p. I25) ${ }^{7}$, procuraram defender e reafirmar a sua identidade cultural africana, encorajados pelas correntes filosóficas e literárias europeias, sendo assim, começou a partir da década de i860, a divulgar a língua, os provérbios e o folclore quimbundo.

Podemos destacar em ordem cronológica, na historiografia dos estudos dos periódicos oitocentistas, as seguintes obras e autores seminais (não obstante, a

\footnotetext{
${ }^{7}$ Os filhos do país, "naturais" da terra, aqueles que foram editores de periódicos e jornalistas, eram críticos ao domínio colonial, formavam um grupo social relativamente homogêneo, daí, por vezes, apresentarem posições contraditórias: a maioria era favorável às guerras de pacificação do gentio promovidas por Portugal.
} 
produção de artigos e livros é muito extensa, o que nos faz correr o risco de omitir alguns trabalhos): Subsídios para a história do jornalismo nas províncias ultramarinas, de Brito Aranha, editada em Lisboa, pela Imprensa Nacional, em I885; o jornalista Teófilo José da Costa, publicou importantes artigos em A Voz de Angola e Tribuna dos Musseques (1965-I974); Carlos Erverdosa, Roteiro da Literatura Angolana, publicado em 1979; Vittorio Salvadorini, Os primeiros números de um jornal de Angola: O Cruzeiro do Sul, apresentado em 1989 na I Reunião Internacional de História da África, sob o tema Relação Europa-África no $3^{\circ}$ quartel do séc. XIX; História da imprensa de Angola, de A. Borges de Melo, publicado em 1993, esse livro faz parte do repositório documental sobre a imprensa angolana; Rosa Cruz e Silva, O nacionalismo angolano. Um projeto em construção no século XIX? Através de três periódicos da época: O Pharol do Povo, O Tomate e O Desastre, apresentado no II Seminário sobre a História de Angola; Fernando Gamboa, A guerra luso-dêmbica, através de um periódico oitocentista angolense (I872-1885), trabalho apresentado no Seminário Encontro de Povos e Culturas em Angola, atividade integrante da Comissão Nacional para as Comemorações dos Descobrimentos Portugueses, em 1997; Marcelo Bittencourt, Dos jornais às armas trajectórias da contestação angolana, I999; por fim, o livro A Imprensa e o império na África portuguesa, I842-1974, resultado da tese de doutoramento da pesquisadora Isadora de Ataíde Fonseca. Esse vasto estudo de longa duração da Isadora de Ataíde analisa as dinâmicas da imprensa e do jornalismo nos territórios compreendidos como a África portuguesa (Cabo Verde, Angola, Moçambique, São Tomé e Príncipe e Guiné). Nesse estudo de caso, Isadora demonstra que a imprensa e o jornalismo nos cinco territórios apresentaram dinâmicas e características similares no período colonial, e que a imprensa foi decisiva na afirmação do colonialismo português, mas o jornalismo também contestou e opôs-se ao projeto imperial.

Para o pesquisador João Pedro da Cunha Lourenço a generalização de Júlio de Castro Lopo revela pouca profundidade analítica, ao caracterizar de forma homogênea 5 décadas de periodismo do século XIX como episódica e amadora (LOURENÇO, 20I9, s/p). O Mercantil foi tido como o primeiro periódico profissional de Angola, durou 27 anos. A longa duração é um sinal de que esse meio de comunicação havia conquistado o grande público e teve leitores ativos durante muito tempo. A Civilisação da África Portuguesa, O Cruzeiro do Sul, dentre outros, também foram periódicos respeitáveis, dentro das condições técnicas e tecnológicas do seu tempo. Para garantir a confiança 
do público leitor os editores tinham que demonstrar posturas éticas. Vejamos o seguinte exemplo:

No nosso $n .^{\circ} 42$ apenas demos aos nossos leitores uma notícia sucinta, mais exacta, sobre os acontecimentos do Ambriz, como nos permitiu a falta de tempo e o recomendava a prudência para não sermos falsos noticiadores (LOURENÇO, 20I9, s/p).

Preocupações com a profissionalização existiam desde o surgimento da imprensa livre, e em I894, nota-se uma consciência coletiva, onde se falava de critérios de admissão e conduta profissional. Sobre as condições técnicas, havia poucos especialistas no domínio dos prelos, os primeiros tipógrafos da imprensa livre eram os mesmos do BOA. Era comum anúncios aceitando candidatos a aprendizes para composição nas tipografias nas décadas de i860 e I870. "Os nossos compositores e impressores são moços africanos de quinze anos que acabam de sair da aula de leitura, e nem sequer tinham entrado numa oficina tipográfica antes de aberta a nossa" ${ }^{8}$. As tipografias não imprimiam somente periódicos, era impresso todo tipo de material. Ter a sua própria tipografia revelava uma certa autonomia financeira, mas, nem todos a possuíam, o Aurora, o terceiro semanário fundado em Angola, em I856, era impresso na tipografia do governo, $O$ Desastre na tipografia do Arauto Africano, esses são apenas alguns exemplos. As edições passaram a ser numeradas, de modo que os leitores pudessem saber se tinham perdido algum exemplar.

\footnotetext{
${ }^{8}$ A Civilisação da África Portuguesa, 3I de janeiro de i867. Acervo Biblioteca Nacional de Portugal. Coleção Fundo Geral Monografias, cota 5150.
} 


\section{C) GitistóñICA}

Figura I: Anúncio dos Serviços Prestados pela Tipografia do periódico União Áfrico Portuguesa

\section{TYPOGRAPHIA UNIÁO}

A officina typographica d'este periodico executa trabalhos typographicos em todos os generos, circulares, contas correntes, programmas, prospectos, editaes, minutas, convites para bailes, partecipaçoes de casamento, de baptisado o do enterro, tarjas, bilhetes de lojas, recibus, carimbus em carlào, lettras, iacturas, preges correntes, registos, diplornas, passaportes, couhecimentos, $\mathrm{rH}$ latorios, maníestos, avisos de publicida. de, mappas, musi oriaes.

Encarrega-se de enconmendas do illterior, e satisiará a qualyuer pedido.

Recommenda-se este estabelecimento pela modicilad"e dos seus preģos e nitidez na execução dos trabalhos.

Fonte: Biblioteca Nacional de Portugal. Coleção Fundo Geral Jornais, A-I, n.6.

Suas fontes de informações consistiam nas narrativas e relatos dos sujeitos envolvidos no fato, em relação ao exterior, os periódicos de maior circulação tinham correspondestes em São Tomé, Moçambique e Lisboa. A Civilisação da África Portuguesa reproduzia artigos assinados publicados no jornal Gazeta de Portugal e no Jornal de Lisboa. Alguns artigos debatidos na Civilisação tiveram reflexo nos jornais portugueses. O Jornal de Lisboa9, do redator Carlos Barreiros, que defendia politicamente a monarquia constitucional, em sua seção Colônias, mostrava-se preocupado com a "desordem" e a "anarquia" promovida pela Civilisação. Esse jornal metropolitano, informava ainda que, os redatores d'A Civilisação haviam "[...] ofendido atrozmente todos os oficiais da província, com raras exceções". Para o Jornal de Lisboa, o artigo, ao ofender os militares, mostrava-se atrevido, imprudente e descomedido, com falta de senso, "tornando até o Sr. Governador responsável por não haver tomado providências, como se pudesse providenciar[...]" ${ }^{\text {.0 }} \mathrm{O}$ impresso lisboense esperava que o procurador da coroa providenciasse interrogar os redatores em virtude das agressões

\footnotetext{
9 Jornal de Lisboa, 19 de fevereiro de 1867. Acervo Biblioteca Nacional de Portugal. Coleção Fundo Geral Jornais, cota J. 572 G.

Io Idem.
} 


\section{C) HitșTórica}

às autoridades. Essas indignações foram em virtude da publicação dos artigos, Câmara Municipal e Administração Geral ${ }^{\text {II }}$ e Governo Militares ${ }^{12}$, onde A Civilisação apontava casos de corrupção na classe militar.

São bem humildes as aspirações deste periódico. A sua atitude na imprensa é a de suplicante. Pede luz para estas trevas. Pede ordem para este cabo. Suplica a todos os que pensam e sentem, a todos quanto são capazes de abnegação e de patriotismo, que ponham em comum os esforços de sua inteligência, e estudem, os que disso são capazes, as causas que entorpecem o desenvolvimento desta sociedade onde só temos em palavras o que lá fora são fatos. ${ }^{13}$

Em I896 a revista Mercantil, que até I89I circulara como periódico, afirmava que possuía agentes de divulgação e comercialização em Lisboa, Ilha da Madeira, Cabo Verde e São Tomé e Príncipe; em Angola nas seguintes regiões: Baylundo, Pungo Andongo, Gampangombe, Benguela, Catumbela, Ambriz, Novo Redondo, Mossamedes, Chibia, Cazengo, Dondo, Icolo e Bengo, Golungo Alto, Ambaca, Massangano, Cabinda, Malange, Canhoca, Quifangondo, N'Dalla-Tando.

As portarias, nomeações, exonerações, decretos e ofícios publicados no $B O A$, a depender do seu teor, tornavam-se fatos políticos nos periódicos. Notamos que o periodismo angolano, em seu conjunto, correspondia às necessidades informativas da população, dentro das suas limitações tipográficas, pois não evidenciamos críticas sistemáticas aos perfis editoriais. Nos artigos, ainda que a objetividade seja impossível, os fatos e as opiniões não se separavam no discurso periodista.

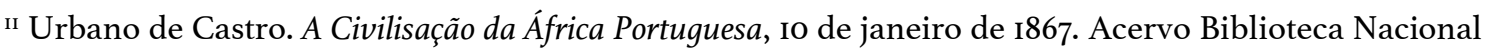
de Portugal. Coleção Fundo Geral Monografias, cota 5150.

${ }^{12}$ Urbano de Castro. 24 de janeiro de I867, op. cit. s/p.

${ }^{13}$ BAYÃO, Francisco Antonio Pinheiro. Cruzeiro do Sul - órgão dos interesses das províncias ultramarinas. I6 de junho de I873. Acervo Biblioteca Nacional de Portugal. Coleção Fundo Geral Jornais, A-I, n. I.
} 


\section{C) Hitistór RICA}

Figura 2: No frontispício, nota-se que a palavra "civilização" apresenta-se em destaque, o seu tamanho é desproporcional à palavra África.

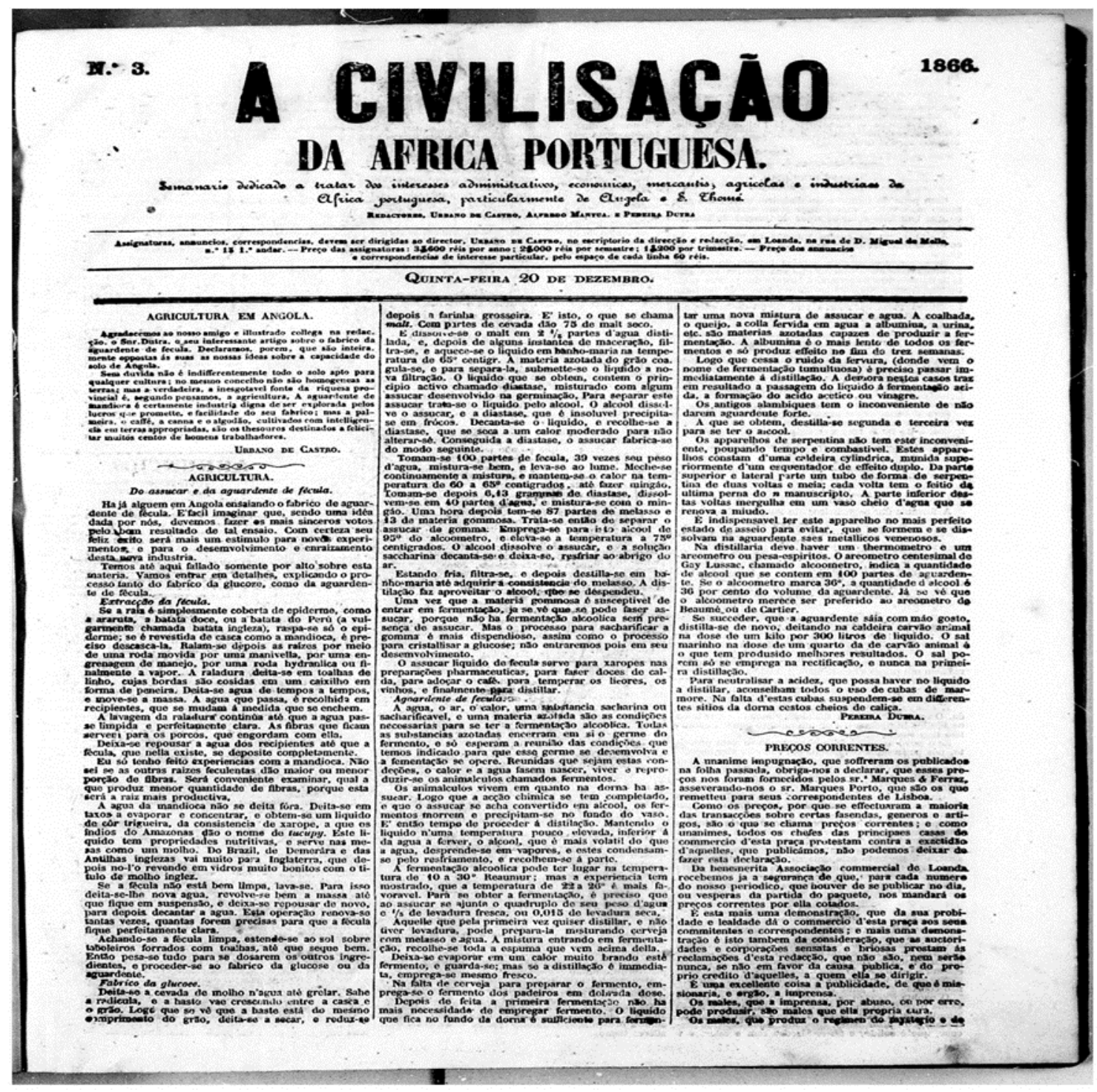

Fonte: Acervo Biblioteca Nacional de Portugal. Coleção Fundo Geral Monografias, cota 5I50.

É fundamental analisar neste estudo a extensão e o efeito da imprensa sobre as mudanças de atitude e mentalidade nos sujeitos históricos diretamente envolvidos, considerando, dessa forma, todos os aspectos do sistema de comunicação. No ano de I867, por exemplo, o governador geral mandou suprimir o periódico A Civilisação da África Portuguesa, porque considerou subversivo o artigo que criticava a sua atuação como autoridade política. O grau de recepção também pode ser medido pelas cartas dos leitores, com suas posições, por vezes, contrárias aos editores. Ainda que as cartas enviadas passassem por um processo seletivo pelos editores, não obstante, para 
demonstrar credibilidade, fazia-se necessário apresentar às ideias divergentes. Na edição de janeiro de I867, o assinante, Sr. Ricardo de Carvalho, argumentava no seu artigo, apresentando suas razões, a favor da escravidão, divergindo da posição do periódico que se autodenominava abolicionista. Rosa Cruz e Silva aponta para a excelente receptividade dos moradores dos concelhos, aos jornais que chegavam de Luanda, por vezes manifestavam adesão aos textos mais polêmicos e os números publicados eram logo esgotados. Isso fica ainda mais evidente quando realizamos leituras a contrapelo a partir dos discursos dos censores (governadores): “[...] até os pretos rudes das cubatas de capim compram e depois de uma leitura lá, comentam os seus a seu modo [...]" (SILVA, 20I8, s/p). Ou ainda, quando foram apreendidos os prelos do periódico $O$ Mercantil, o governador geral justificou-se da seguinte forma:

[...] pelos danos que da sua publicação provinha a causa pública, e pela constante rebelião, exaltando as forças do inimigo, e deprimindo as nossas tropas, e pela divulgação de notícias graves, que antes de se poderem averiguar e convencer de falsas, ocasionavam a desanimação pública, e entretinham o desfalecimento do comércio e indústria; havendo por todos estes perniciosos efeitos, veementes conjecturas a tranquilidade pública; e integridade do domínio da corôa portuguesa nesta possessão... (SILVA, 20I8, s/p)

O ministro Sá da Bandeira tinha plena convicção do papel ativo da imprensa na vida cotidiana da província. Temos como exemplo, dentre outros, às denúncias contra o serviço forçado dos pretos livres, denominado serviço dos carregadores, prática abolida pelo decreto de 3 de setembro de I856. Os artigos publicados nos periódicos constituíam-se em elemento de prova, dos abusos, do desprezo com a lei, “abertamente desobedecida e sofismada ${ }^{\mathrm{I} 4 "}$.

Como prova d'essa asserção poderiam citar-se centenas de factos; bastará, porém, agora referir o seguinte, mencionado recentemente pela imprensa angolense; diz ela: «que no concelho da Barra do Bengo continua o apresamento de gente, que o chefe obriga ao corte do capim, que d'ali diariamente embarca para provimento das

\footnotetext{
${ }^{14}$ Quando foi publicada essas posições, Sá da Bandeira não era mais ministro da Marinha
} (BANDEIRA, I874, p. 8.). 


\section{C) Hitistór RICA}

abegoarias e cavalariças do Loanda: e que por isso, se tem despovoado aquele concelho. ${ }^{15}$

Sá da Bandeira temia que em meio a tirania dos senhores escravagistas exercida contra os indígenas e as injustiças praticadas para com eles, sob a complacência de algumas autoridades coloniais, se tornasse um perigo permanente para o domínio português e para a segurança dos indivíduos brancos que habitavam nas colônias, ao "exaltar as forças do inimigo". Advertia aos escravagistas que não respeitavam a legislação, que, com a existência da imprensa livre, e de possíveis periodistas agitadores, suscitando o ódio, poderia surgir perturbações sociais com manifestações de atos de vingança por parte dos africanos. ${ }^{16}$

${ }^{15}$ Idem, p. IO.

${ }^{16}$ Ibidem. 


\section{C) Histótórica}

Figura 3: Frontispício do periódico O Mercantil

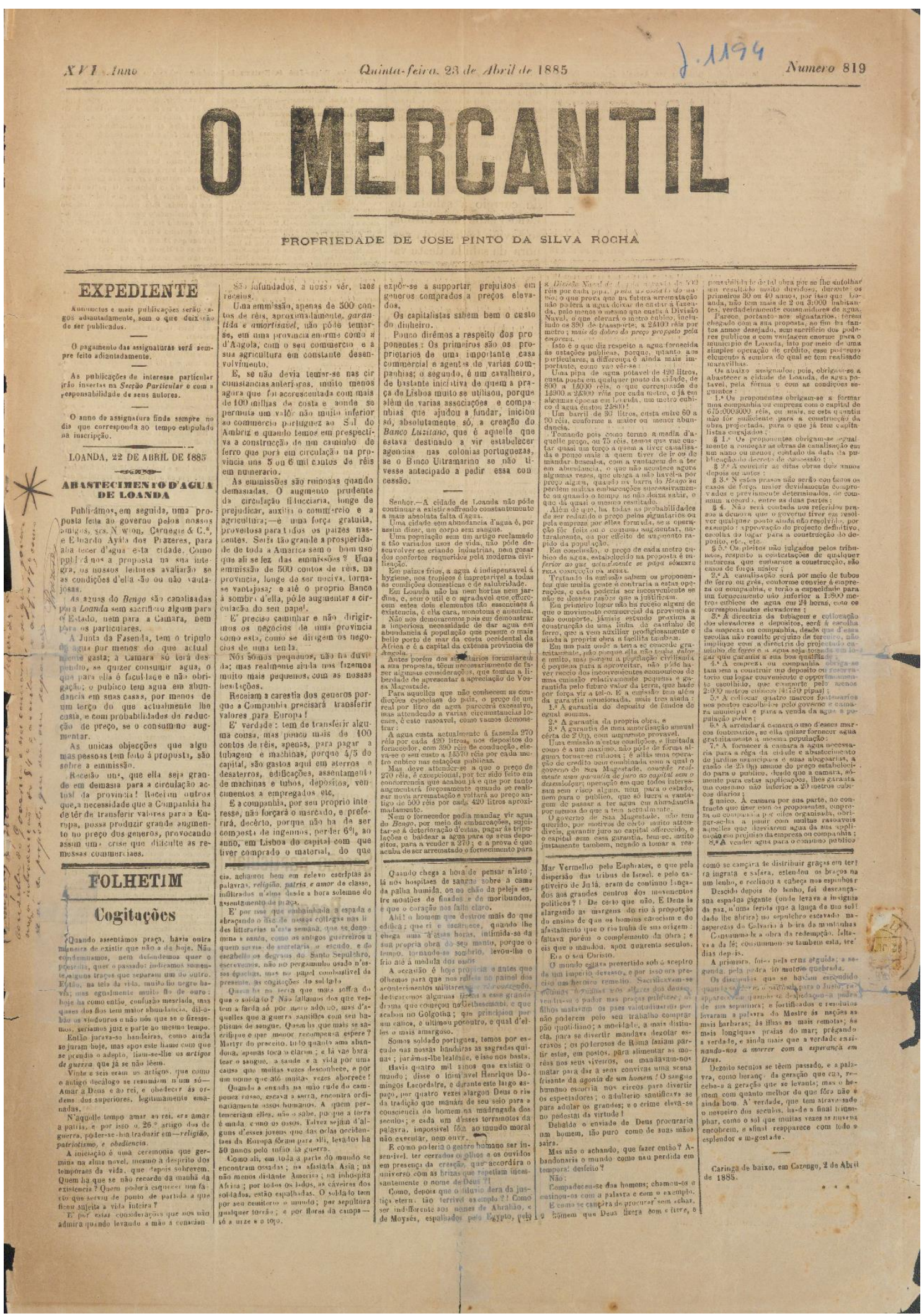

Fonte: Acervo Biblioteca Nacional de Portugal. Coleção Fundo Geral Monografias. 


\section{C) GitistótóRICA}

Resoluções que procuravam controlar às práticas denominada pela administração colonial como "abuso de liberdade de imprensa ${ }^{\mathrm{I} 7}$ " foram promulgadas antes do advento da imprensa livre, independente ou não oficial, em Cabo Verde, Angola, Moçambique, São Tomé de Príncipe e Guiné Bissau. O decreto determinava que os juízes de primeira instância das comarcas do ultramar seriam competentes para julgarem os crimes cometidos por abuso de liberdade de imprensa, segundo o ministro Sá da Bandeira, era necessário regular tais violações, uma vez que ainda não havia sido discutido nas Cortes a proposta de lei sobre esse objeto. Acreditamos que o clima de contestação e protesto dos comerciantes de Luanda e Benguela em defesa dos interesses da elite euro-africana, sob a direção do Arsénio Pompílio Pompeu de Carpo e do Joaquim António de Carvalho e Meneses, em I853, dentre outros fatores, suscitou a "necessidade" de regulação da imprensa. Arsénio de Carpo publicou uma série de panfletos sobre política e assuntos pessoais, contribuiu com vários artigos para os jornais metropolitanos, contudo, devido a defesa das causas do grupo social que defendia, foi considerado uma ameaça à ordem pública e aos interesses metropolitanos. Chegou a convidar publicamente o povo de Angola a defender o seu direito de emancipar-se de Portugal (CORRADO, 2007, s/p).

"Ficam abolidas todas as cauções e restrições estabelecidas para a imprensa periódica pela legislação atualmente em vigor". ${ }^{8}$ A partir dessa autorização, por meio do decreto de 22 de maio de I866, do Ministério dos Negócios Eclesiásticos e de Justiça, mais, especificamente, da Direção Geral dos Negócios da Justiça, assistimos o início da imprensa de cunho liberal. O mesmo decreto que anunciava a liberdade também trazia no seu bojo a censura. No artigo $2^{\circ}$, expressava que o nome do editor deveria ser enviado oito dias antes da publicação para o administrador do conselho ou bairro e perante o delegado do procurador régio da comarca ou vara. A falta de declaração incorria em pena de três dias a três meses de prisão e multa correspondente. No artigo quinto, aos crimes de abuso de manifestação do pensamento, eram aplicáveis às penas respectivas estabelecidas no código penal. ${ }^{19}$ Neste trabalho, temos apresentado várias situações de censura. Em I88I, o periodista Arantes Braga, foi acusado pelo crime de injúria, cuja sentença em primeira instância o condenara a 5 (cinco) anos de suspensão

\footnotetext{
${ }^{17}$ Boletim do Governo Geral da Província de Angola, 12 de fevereiro de i857.

${ }^{18}$ Decreto de 22 de maio de I866, do Ministério dos Negócios Eclesiásticos e de Justiça, Direção Geral dos Negócios da Justiça.

I9 Pharol do Povo, I7 de março de I883. Acervo Biblioteca Nacional de Portugal. Coleção Fundo Geral Jornais, A-I. n.5.
} 


\section{C) Citceatórica}

dos direitos políticos que, através de acórdão, foi comutada para 40 dias de prisão. ${ }^{20}$ Sucessivos decretos foram determinando novas punições, como por exemplo, o de II de agosto de I898, que estabelecia que todos os crimes de abuso de liberdade de imprensa seriam julgados em processo de polícia correcional, qualquer que fosse a pena aplicável.

Em linhas gerais, essa imprensa oitocentista foi mais opinativa e ideológica (imprensa de opinião) que de notícias, mas sobretudo, um fórum de discussão, um órgão de opinião pública. A mudança do tom opinativo para o relato de notícias do cotidiano só aconteceu nas primeiras décadas do século XX.

\section{Referências Bibliográficas}

Autores Angolanos. Voz de Angola Clamando no Deserto - oferecida aos amigos da verdade pelos naturais. Lisboa: Typographia, I90I. Neste trabalho fizemos uso da edição facsimilar: Autores Angolanos. Voz de Angola Clamando no Deserto. Lisboa: Edições 7o, Luanda: União dos Escritores Angolanos, 1984.

BANDEIRA, Marques de Sá da. A emancipação dos libertos. Carta dirigida ao excelentíssimo senhor Joaquim Guedes de Carvalho e Menezes, Presidente da Relação de Luanda. Lisboa: Imprensa Nacional, I874.

BARROS, José D'Assunção. Fontes históricas - uma introdução aos seus usos historiográficos. Simpósio Temático sobre Fontes Históricas, Encontro da ANPUH, 2019.

BENJAMIN, Walter. Sobre o conceito da História. In: Obras Escolhidas. I: Magia e técnica, arte e política. Tradução de Sergio Paulo Rouanet. São Paulo: Brasiliense, 1985

BITTENCOURT, Marcelo. Dos jornais às armas - trajetórias da contestação angolana. Lisboa: Editora Vega, 1999.

BRASIL, Eric \& NASCIMENTO, Leonardo Fernandes. História digital: reflexões a partir da Hemeroteca Digital Brasileira e do uso de CAQDAS na reelaboração da pesquisa Histórica. Rio de Janeiro: Estudos Históricos, vol 33, nº 69, p. 196-219, janeiro-abril 2020.

\footnotetext{
${ }^{20}$ Informação presente na seção Noticiário do Jornal de Loanda, 6 de outubro de I88I. I896 - O Decreto de 26 de novembro estabelecia a punição como crime de abuso de liberdade de imprensa a todos os que se cometerem com publicidade, por qualquer meio de impressão, ou estampagem, periódica ou não periódica, independentemente do tamanho. I898 - O Decreto de II de agosto estabelecia que todos os crimes de abuso de liberdade de imprensa seriam julgados em processo de polícia correcional, qualquer que fosse a pena aplicável.
} 
CORRADO, Jacopo. The Rise Of A New Consciousness: Early Euro-African Voices of Dissent in Colonial Angola. e-JPH, Vol. 5, number 2, Winter 2007.

CRUZ, Heloísa de Faria \& PEIXOTO, Maria do Rosário da Cunha. Na oficina do historiador: conservas sobre história e imprensa. Projeto História: Revista do Programa de Estudos Pós-Graduandos em História do Departamento de História da Pontifícia Universidade Católica de São Paulo, São Paulo, n³5, p. 255-272, dez, 2007.

DARNTON, Robert \& ROCHE, Daniel. Revolução Impressa - a imprensa na França I775I80o. São Paulo: Editora da Universidade de São Paulo, I996.

DE LUCA, Tânia Regina. História dos, nos e por meio dos periódicos. In: PINSKY, Carla Bassanezi (Org.) Fontes Históricas. São Paulo: Editora Contexto, 2005.

DIAS, Jill. \& VALENTIN, Alexandre. Nova História da Expansão Portuguesa. O império africano - I825-I89o. Lisboa: Editora Estampa, I998.

FONSECA, Isadora de Ataíde. A imprensa e o império na África portuguesa - I842-1974. Lisboa: Edições 70, 2019.

HOHLFELDT, Antonio \& CARVALHO, Caroline Corso. A imprensa angolana no âmbito da história da imprensa colonial de expressão portuguesa. São Paulo, v.35, n.2, p. 85-Ioo, jul/dez. 2012.

LAINS, Pedro. Causas do colonialismo português em África, I822-I975. Instituto de Ciências Sociais da Universidade de Lisboa. Análise Social, vol. 33, nºI46/I47, I998.

LOPO, Júlio de Castro. Jornalismo de Angola - subsídios para sua história. Luanda: Centro de Informação e Turismo de Angola, 1964 .

. Para a História do Jornalismo de Angola. Luanda: Museu de Angola, 1952.

LOURENÇO, João Pedro da Cunha. A dinâmica e o estatuto dos Jornalistas em Angola no periodo da imprensa livre (I866-I923). União dos Escritores Angolanos. https://www.ueangola.com/criticas-e-ensaios, consulta em I2 de maio de 2019.

MILLER, Joseph C. History and Africa/Africa and History. The American Historical Review. v. IO4, n. I, I999. 
MORENO, Helena Wakim. Notas sobre o embate racial na imprensa de Luanda (I893-I9OI).

São Paulo: Anais do XXVI Simpósio Nacional de História - ANPUH, julho 2011.

PÉLISSIER, René; WHEELER, Douglas. História de Angola. Lisboa: Tinta da China, 2016.

PINTO, Alberto de Oliveira. História de Angola - da pré-história ao início do século XXI. $2^{\circ}$ edição. Lisboa: Mercado de Letras Editores, 2017.

PINSKY, Carla Bassanezi (org.). Fontes Históricas. São Paulo: Contexto, 2005.

BECKER, Jean-Jacques. A opinião pública. In: RÉMOND, René (org.). Por uma história política. Rio de Janeiro: Editora FGV, 2003.

Relatório do Governo Geral da Província de Angola. Sebastião Lopes de Calheiros e Menezes. I86I. Lisboa, Imprensa Nacional, I867.

Relatórios dos governadores das províncias ultramarinas. Relatório do Governo Geral da Província de Angola - I887. Ministério da Marinha e Ultramar, Lisboa, Imprensa Nacional, 1889 .

RIBEIRO, Elaine. A escrita como instrumento de reivindicação dos carregadores do comércio de longa distância da Lunda. Novas possibilidades de pesquisa a partir das fontes missionárias. Juiz de Fora: Locus - revista de história, v. 23, n. 2, p. 23I-25I, 2017.

SANTOS, Eduardo A. Estevam. Imprensa, raça e civilização: José de Fontes Pereira e o pensamento intelectual angolano no século XIX. Salvador: Revista Afro-Ásia, n. 6I, p. II8I57, 2020.

Antonio Urbano Monteiro de Castro: a imprensa a serviço da dominação colonial portuguesa em angola oitocentista. Cadernos de África Contemporânea, vol. 03, $\mathrm{n}^{\circ} .6,2020$.

Angola, entre o passado e o futuro: história, intelectuais e imprensa (I870-I900). Revista de Teoria da História, Vol. 22, nº 02, 2019.

SILVA, Rosa Cruz. Construindo a história de Angola - as fontes e sua interpretação. União dos Escritores Angolanos. <http://www.ueangola.com/criticas-e-ensaios/item/72construindo-a história-angolana-as-fontes-e-a-sua-interpretação>, consulta em I2 $\backslash 04 \mid 2018$. 


\section{C) HistontóricA

. Os periódicos como fonte de pesquisa histórica - a imprensa escrita de Angola

do séc. XIX. Luanda: Ministério da Cultura, Arquivo Histórico Nacional, 1993.

Recebido em: I3 de outubro de $202 I$.

Aprovado em: 30 de novembro de 2021 . 